\title{
Intergroup Differentiation in Social Context: Identity Needs versus Audience Constraints
}

\author{
Naomi Ellemers; Cathy van Dyck; Steve Hinkle; Annelieke Jacobs \\ Social Psychology Quarterly, Vol. 63, No. 1. (Mar., 2000), pp. 60-74.
}

Stable URL:

http://links.jstor.org/sici?sici=0190-2725\%28200003\%2963\%3A1\%3C60\%3AIDISCI\%3E2.0.CO\%3B2-M

Social Psychology Quarterly is currently published by American Sociological Association.

Your use of the JSTOR archive indicates your acceptance of JSTOR's Terms and Conditions of Use, available at http://www.jstor.org/about/terms.html. JSTOR's Terms and Conditions of Use provides, in part, that unless you have obtained prior permission, you may not download an entire issue of a journal or multiple copies of articles, and you may use content in the JSTOR archive only for your personal, non-commercial use.

Please contact the publisher regarding any further use of this work. Publisher contact information may be obtained at http://www.jstor.org/journals/asa.html.

Each copy of any part of a JSTOR transmission must contain the same copyright notice that appears on the screen or printed page of such transmission.

The JSTOR Archive is a trusted digital repository providing for long-term preservation and access to leading academic journals and scholarly literature from around the world. The Archive is supported by libraries, scholarly societies, publishers, and foundations. It is an initiative of JSTOR, a not-for-profit organization with a mission to help the scholarly community take advantage of advances in technology. For more information regarding JSTOR, please contact support@jstor.org. 


\section{Intergroup Differentiation in Social Context: Identity Needs versus Audience Constraints*}

NAOMI ELLEMERS

Leiden University

CATHY VAN DYCK

Free University, Amsterdam

STEVE HINKLE

Miami University

ANNELIEKE JACOBS

Free University, Amsterdam

In this paper we investigate intergroup differentiation in different social contexts. Although low group status motivates group members to display biases favoring the in-group, the awareness that others perceive their group as having low-status may prevent them from openly claiming in-group superiority. The interplay between these two considerations may account for inconsistency in findings in the literature regarding displays of in-group favoritism in lower-status-groups. In two experiments we investigate whether people rate their group differently (1) in private and in public situations, (2) in intragroup and in intergroup contexts, and (3) when their strength of in-group identification differs. Results show that members of lower-status groups are more likely to acknowledge in-group inferiority in public than in private situations. Furthermore, strength of identification affects the relative importance of different audiences: High identifiers adapt their responses in an intragroup situation, while low identifiers are more sensitive to the audience in an intergroup context.

In investigations of the occurrence of biases in group ratings, it is generally assumed that members of lower-status groups should be more inclined than those of higher status-groups to conjure up a favorable image of their group. Empirical studies, however, have not revealed such a straightforward relation between relative group status and displays of in-group favoritism. In the present paper we examine

* These studies were presented at the eleventh general meeting of the E.A.E.S.P., held in Gmunden July 1996. The data for the first study were collected when Cathy van Dyck visited Steve Hinkle at the University of Kent as an exchange student; the data for the second study were collected by Cathy van Dyck and Annelieke Jacobs as part of a practical research assignment. The authors would like to thank Manuela Barreto for her constructive comments on a previous draft of this manuscript.

Address to correspondence to Naomi Ellemers, Social and Organizational Psychology, Leiden University, P.O. Box 9555, 2300 RB Leiden, the Netherlands (Email: Ellemers@fsw.leidenuniv.nl). the social context in which group ratings are given, and the extent to which people identify with the in-group, as factors that are likely to affect group members' inclination to show judgments favoring the in-group, or to refrain from doing so.

The core assumption of the social identity approach to intergroup relations is that people's self-concept is implicated in the social groups to which they belong (Tajfel 1974, 1975). As a result, the possibilities of establishing a positive social identity are limited for members of groups that have inferior social standing. Consequently, social identity theory has specified different coping strategies that people may use when confronted with such threats to identity (Tajfel 1978, Tajfel and Turner 1979).

One possible response, which has attracted considerable attention from empirical researchers, is to challenge the current state of affairs by systematically assigning more positive evaluations or more favorable 
outcomes to the in-group than to relevant out-groups. In fact, a considerable amount of research, both with experimentally created laboratory groups and with natural groups, has tried to establish whether members of lower-status groups are more inclined to show in-group favoritism on such measures than members of high-status groups. Previous research has not revealed a systematic or straightforward relationship between relative group status and in-group favoritism (for overviews see Brewer 1979, Messick and Mackie, 1989, Mullen, Brown and Smith 1992). Instead, different studies have revealed that positive, zero, or negative correlations between group status and in-group favoritism may occur (Hinkle and Brown 1990).

This point is consistent with the original formulation of social identity theory, in which Tajfel and Turner stated that there is

\begin{abstract}
. . . a great deal of evidence that minority or subordinate group members . . . frequently tend to derogate the in-group and display positive attitudes toward the dominant outgroup. In other words, deprived groups are not always ethnocentric in the simple meaning of the term; they may, in fact, be positively oriented toward the depriving out-group. (Tajfel and Turner 1979:36-37).
\end{abstract}

To understand why this may be the case, we must keep in mind that in-group favoritism is only one possible route towards a positive social identity. Alternatively, social identity theorists (Tajfel 1978, Tajfel and Turner 1979, Van Knippenberg 1989) have argued that, depending on the specific circumstances, members of lower-status groups may adopt other identity management strategies. For instance, people also may opt to dissociate themselves from the inferior ingroup (individual mobility; see Ellemers, Spears and Doosje 1997), or may propose alternative criteria for establishing the group's relative standing (social creativity; see Ellemers 1993, Van Knippenberg and Ellemers 1990). Thus, although the confrontation with inferior in-group status generally motivates group members to improve their social identity, social identity theorists believe that this situation does not necessarily result in displays of in-group favoritism.
When trying to specify the conditions under which in-group favoritism is likely to occur, we must consider that claims of ingroup superiority by lower-status group members entail a denial of established intergroup differences. In fact, among lower-status group members, displays of in-group favoritism emerge when the intergroup comparison is more ambiguous-for instance, because status differences seem unstable, or when the measure for in-group favoritism is not directly related to the status criterion (see Ellemers and Van Rijswijk 1997; Lemaine 1974; Mummendey and Schreiber 1983, 1984; Mummendey and Simon 1989; Van Knippenberg and Van Oers 1984; Van Knippenberg and Wilke 1979).

What psychological process underlies such differentiated patterns of in-group favoritism? This question has not yet been answered. Tajfel and Turner have suggested that members of subordinate social groups perhaps "internalize a wider social evaluation of themselves as inferior" (emphasis added). In this sense they build on the earlier work of Tajfel $(1974,1975,1978)$, who argues that those who are socially disadvantaged may come to accept this situation as legitimate or just (and hence refrain from attempts to redress their disadvantage), when they see no feasible alternatives to the status quo. In this paper, however, we wish to explore an alternative possibility: that members of a group with lower social standing acknowledge the out-group's superiority because in-group favoritism simply does not seem feasible as an identity management strategy, given the circumstances. Thus, in the present study, we aim to investigate the extent to which judgments favoring the ingroup reflect people's internalized convictions about their group's relative worth (as assumed by Tajfel and Turner 1979), or result from strategic adjustments of the in-group's superiority claims to consensual views on their group's current standing.

A similar problem was addressed in a recent study in which the authors identified different reasons why people may try to refrain from showing prejudice against others. Plant and Devine (1998) investigated whether similar or different judgments of the same target were obtained under private 
and public conditions, depending on whether the desire to respond without prejudice stemmed from internal convictions or from external pressures. They observed equal responses in public and private conditions for those who had internalized the desire to respond without prejudice. By contrast, externally motivated participants did not display prejudicial judgments in public, although they privately endorsed stereotypical views of the group in question.

In line with this argument, for the two studies reported here, we begin with the idea that relative group status can have two different and possibly contradictory effects. One possibility is that members of a group with relatively low-status come to internalize their group's inferior standing, as reflected in the ratings of their group, regardless of the circumstances under which these ratings are expressed. Alternatively, it may be that low-status group members continue to think highly of their group, and are highly motivated to establish positive in-group distinctiveness. At the same time, however, they may find it difficult to deviate from consensual (or perhaps even evidence-based) views about their group's relative worth; as a result they may bring their claims of in-group superiority into line with established social perceptions. As in the results obtained by Plant and Devine (1998), we predict differential group ratings, depending on whether private or public responses are examined.

So far our discussion has focused on members of lower-status groups because they are most likely to experience a conflict between their motivation to establish a positive group image (on the one hand), and the perceived credibility of such behavior (on the other). By contrast, members of groups with superior social standing are less likely to feel restricted by similar considerations when they are publicly accountable for their group ratings. Consequently there is no reason to assume a difference between private and public intergroup judgments when the in-group has high-status. Yet it is not self-evident that members of high-status groups should display judgments favoring the ingroup. In fact, their established superiority, which (on the one hand) would justify such behavior, implies (on the other hand) that further public enhancement of their social standing may seem unnecessary.

\section{STUDY 1}

In the first experiment we differentiated between members of natural groups who perceived their group as having either high or low social status. We aimed to assess whether displays of in-group favoritism among those with high or low self-perceived group status differed, depending on whether their group ratings remained private or were to be given in public. In line with our previous argument, we predict that the amount of in-group favoritism displayed is determined interactively by the self-perceived group status and by the social context in which the group ratings are made. Specifically, we hypothesize that public versus private context of responses has no effect for those who perceive their group as having high-status, whereas those who feel that they belong to a lower-status group should be more likely to display in-group favoritism in their private judgments than in their public group ratings.

\section{METHOD}

\section{Participants and Design}

In the first study, 89 students ${ }^{1}$ ( 38 women and 51 men) participated voluntarily. To increase their motivation, we rewarded participation in the study with a lottery ticket, which could earn them 30 pounds sterling. All participants belonged to one of 16 sports societies at the University of Kent at

\footnotetext{
${ }^{1}$ The data from six outliers (five male participants and one female) were excluded from the final analysis because their scores on the measure of self-perceived status (which we used as an independent variable) as well as their scores on the dependent variables departed from the mean by more than two standard deviations. These students participated in different experimental conditions; when we include them in the analysis, the means patterns on both ingroup favoritism measures remain very similar, and are consistent with our prediction. The multivariate two-way interaction, however, does not reach the conventional significance level $(F(2,80)=2.37, p=$ $.10)$, and the predicted contrast between private and public conditions for participants with low self-perceived status is only marginally significant (multivariate contrast: $F(2,81)=3.05, p<.053)$.
} 
Canterbury. ${ }^{2}$ In each experimental session, members of two different sports societies participated, up to a maximum of six members from the same society. ${ }^{3}$ We used a 2 (self-perceived status: high/low) by 2 (nature of responses: public/private) between-subjects factorial design. At the end of the experiment, all participants were fully debriefed and thanked for their cooperation.

\section{Procedure}

Upon arrival, participants were informed that the experimenters intended to examine how players of various sports performed on a sports perception task, by comparing the performance of members of different sports societies.

Self-perceived status. To assess participants' self-perceived status, we selected two items from Crocker and Luhtanen's (1990) Public Collective Self-Esteem scale, and adapted it to refer to a particular group, namely the sports society to which the participant belonged (also see Long and Spears, 1997). Participants were asked to indicate on a scale from 1 (strongly disagree) to 9 (strongly agree) the extent to which they agreed with the folowing items: "In general others respect [my sports club]" and "Most

\footnotetext{
${ }^{2}$ We selected these groups from the 36 sports societies at this university, on the basis of a pilot study in which we asked students $(N=64)$ to rate the prestige of each society. For the main study, we excluded societies that had received extremely favorable or unfavorable ratings, so that the actual status of the societies that were selected for the main study would be ambiguous.

${ }^{3}$ Although we aimed for equal numbers of participants representing different societies, in several experimental sessions we experienced a minority/majority representation. In those cases we carefully explained that the groups' performances could not be affected by the number of participants present in a specific session. Furthermore, we coded for relative in-group size during the experimental session, so as to be able to check for unintended effects. Additional analyses revealed that, overall, those in a minority position displayed more in-group favoritism than did majority-group members $(F(1,79)$ $=4.93, p<.01$ ), in agreement with previous work on group size effects (e.g., Ellemers and Van Rijswijk 1997). For our present purposes, it is important that relative group size did not affect self-perceived group status, and that inclusion of relative group size as a covariate in the analysis of in-group favoritism did not affect our main results.
}

people consider [my sports club] to be more ineffective than other clubs" (reverse coded). We used the unweighted mean score on these two items $(r=.49)$ to divide participants at the median (5.5) into those with low $(M=4.26)$ or high self-perceived status $(M=$ $6.99, t(71)=14.63, p<.001)$.

Experimental task. Then participants were asked to perform a "spot-the-ball" task (see $\mathrm{Ng}$ 1986). This task consisted of five pictures that had been taken during matches of various sports. On these pictures, the actual position of the ball had been covered, but similar covers appeared in three alternative places in the picture. Participants were asked to indicate the actual placement of the ball on each of the five pictures. ${ }^{4}$ Although each participant worked individually on a separate set of pictures, they were led to believe that only the aggregate scores of the two groups would be compared. They had no way of knowing whether their answers were correct or incorrect, and in fact we found no systematic performance difference between members of different sports clubs.

Nature of responses. In the private condition, participants were told that their responses to the next two tasks would remain strictly confidential. Participants in the public condition were informed that, at the end of the experimental session, they would have to indicate and discuss their responses publicly with other participants in the experiment (in-group as well as outgroup members).

Dependent measures. To assess the extent to which they favored the in-group, we first asked participants to indicate the relative performance of their group on the "spot-the-ball" task by estimating the average number of correct responses (ranging from 0 to 5) given by the in-group and by the out-group. We emphasized that they had to estimate the performance of these groups

\footnotetext{
${ }^{4}$ In the experiment we used four sets of five pictures each, which were balanced for different sports. These 20 pictures had been selected from an initial set of 42 pictures, on the basis of a pilot study. In that pilot study, 11 independent judges had been asked to rate the difficulty of each picture on a scale from 1 (very easy) to 5 (very difficult). The 20 pictures that we selected for the main study were rated between 2.25 and 3.75 .
} 
as a whole, rather than focusing on those group members who were present at the experimental session. We then explained that participants had been working on different sets of pictures. Therefore participants were given the opportunity to rate the difficulty (from 1 to 5) of different sets of pictures, which we would take into account when determining the relative performance of people who had worked with these sets. It was emphasized, however, that participants would not assess the difficulty of the pictures they had been working on themselves. Instead they were asked to rate one set of pictures that an in-group member allegedly had worked on, and one set that allegedly had been worked on by an out-group member. ${ }^{5}$ Participants were given the impression that their ratings would influence the number of points that could be earned with a particular set. Thus they could also use this measure to favor the in-group by indicating that the in-group's set had been more difficult and hence should be awarded more points than the out-group's set.

\section{RESULTS}

To assess the extent to which participants favored the in-group in their performance ratings and difficulty estimates, we calculated the difference between the points awarded to the in-group and the points awarded to the out-group for each measure. ${ }^{6}$ We then examined these two measures of ingroup favoritism in a 2 (self-perceived status: low/high) by 2 (nature of responses: private/public) MANOVA. This procedure yielded a multivariate significant two-way interaction only between self-perceived status and nature of responses $(F(2,74)=6.12$, $p<.01)$; the predicted effect emerged on both measures of in-group favoritism (performance ratings: $F(1,75)=7.62, p<.01$; dif-

${ }^{5}$ The different sets of pictures that were used for this task were assigned randomly to participants in different experimental conditions, with (alleged) ingroup and out-group sets counterbalanced. These sets did not differ from each other in rated difficulty.

${ }^{6}$ We obtained identical results from an analysis of variance of the raw scores awarded to the in-group and to the out-group, in which the target group is treated as a within-subjects variable. ficulty estimates: $F(1,75)=2.85, p<.10)$. That is, the patterns of means and the posthoc contrasts, as predicted indicate that participants with low self-perceived status express significantly more in-group favoritism privately than in the public condition, whereas the nature of responses has no such effect on in-group favoritism for those with high self-perceived status (See Table 1).

\section{DISCUSSION}

In the introduction we pointed out that if low-status group members have internalized a negative image of the in-group, as suggested in social identity theory, they should refrain from rating the in-group more positively than the out-group, regardless of whether they are giving their responses privately or in public. Instead, however, we obtained the predicted interaction effect, an indication that group members strategically adapt their ratings of the two groups depending on whether their responses are public or private. This finding supports our general argument that the expression of ingroup favoritism does not necessarily reflect the extent to which people actually value their group. In other words, when people think that others hold their group in low regard, they may refrain from claiming ingroup superiority while privately continuing to believe in their group's worth.

The general idea that social context plays an important role in group ratings is consistent with self-categorization theory (Turner 1987), which assumes that people actively use social behavior as a means to communicate to others their position in the social structure. The possible consequences of this practice have been specified in the social identity model of deindividuation phenomena (the SIDE-model; see Reicher, Spears and Postmes 1995, Spears, Lea and Lee, 1990), in which it is argued that people are likely to adapt their social behavior, as a result of normative pressures from others. Accordingly it was demonstrated empirically that when people were publicly accountable for their actions, they displayed only those behaviors which seemed socially acceptable (Reicher and Levine 1993). They were reluctant to behave in accordance with their 
Table 1. Effect of Self-Perceived Group Status and Nature of Responses on Two Measures of In-Group Favoritism (Experiment 1)

\begin{tabular}{lcc}
\hline & \multicolumn{2}{c}{ Nature of Responses } \\
\cline { 2 - 3 } & Private & Public \\
\hline Performance Estimates & & \\
Self-perceived group status & $-.14^{\mathrm{a}}$ & $.09^{\mathrm{a}, \mathrm{b}}$ \\
High & $(.79)$ & $(.52)^{\mathrm{a}}$ \\
Low & $.50^{\mathrm{b}}$ & $-.18^{\mathrm{a}}$ \\
& $(.86)$ & $(.73)$ \\
Difficulty Ratings & & \\
Self-perceived group status & & $.02^{\mathrm{a}, \mathrm{b}}$ \\
High & $.04^{\mathrm{a}, \mathrm{b}}$ & $(.68)$ \\
Low & $(.74)$ & $-.27^{\mathrm{a}}$ \\
& $.23^{\mathrm{b}}$ & $(.45)$ \\
\hline
\end{tabular}

a,b Means differ significantly from each other $(p<.05)$ if their superscripts do not share a common letter. Standard deviations are given in parentheses.

group membership, however, when such behavior was likely to be sanctioned by others (Reicher and Levine 1994).

In this first study we distinguished between group members who differed from each other with respect to the self-perceived status of their group. This self-perception may reflect primarily the extent of their confidence that claims of in-group superiority would constitute a successful strategy to improve their group's image. Yet it does not necessarily refer to the processes specified by self-categorization theory and the SIDEmodel which focus on the normative regulation of group behavior.

Therefore, to look more closely at the normative processes that may affect the expression of biased group judgments, we conducted a second study in which we examined public and private responses to an externally assigned intergroup status difference. We believe that this study more clearly presents group members with some form of normative pressure, in comparison with the relative ambiguity of the self-perceived differences in group status observed in Study 1.

\section{STUDY 2}

If we assume that normative considerations may influence public group ratings, it becomes relevant to assess more closely the nature of the norms that are likely to affect the expression of judgments favoring ingroups. Therefore, in this second study, we examine whether people's public behavior may differ, depending on whether it is directed at an in-group or an out-group audience. According to self-categorization theory, a fundamental asymmetry exists between the two, in the sense that an audience which contains only in-group members can be characterized as an intragroup situation, whereas the presence of out-group members always implies an intergroup social context (also see Young et al. 1997). Consequently we now consider the sense in which the public expression of in-group favoritism is likely to differ, depending on whether group members find themselves in an intra-group social context (in which only other in-group members are present) or an intergroup context (containing both ingroup and out-group members).

In an intragroup context, people are likely to assume that the (in-group) audience has an interest similar to theirs in upholding a positive image of their group. Consequently, when lower-status group members give their group ratings in front of an audience that consists only of in-group members, judgments favoring the in-group are likely to be considered normative. By contrast, in an intergroup situation, the presence of an out-group audience, which is likely to sanction claims of in-group superiority, should suppress biases favoring the in-group in the ratings given by lower-status group members. Thus, in comparing group mem- 
bers' responses in different social situations, it would seem that the public expression of judgments favoring the in-group might differ, depending on the nature of the audience.

In the above argument, we have considered the ways in which external pressures from different audiences are likely to affect displays of in-group favoritism by members of lower-status groups. In addition, however, previous research revealed that particular motivational goals may become salient with specific audiences (see Haslam and Turner 1992, 1995, Oakes 1987, Oakes, Haslam and Turner 1994, Spears and Manstead 1989). In other words, we must consider as well the possibility that the relevant social context also affects group members' internal motivation to indicate their group's relative superiority. From this point of view, we may argue that it is particularly important for members of a lower-status group to uphold their group's worth to the outside world (that is, in an intergroup situation). When aiming to improve the group's current standing through some form of collective action, however, they may find it necessary to acknowledge among themselves (in an intragroup context) that the group's current standing leaves something to be desired. Thus, if we accept that judgments favoring in-groups result from an interplay between internal motivations and external (normative) pressures, we must keep in mind that different social contexts not only may determine the anticipated acceptability of in-group superiority claims (as a result of external pressures), but also are likely to elicit different motives guiding group members' behavior (their internal considerations).

Consequently the predicted effects of an intragroup and an intergroup public context may differ. When we focus on the effects of external pressure in public situations, it would seem that exposure to an ingroup audience (intragroup context) may enhance displays of in-group favoritism, whereas the presence of out-group members (intergroup context) should cause lower-status group members to refrain from claiming in-group superiority. Yet insofar as the social context elicits specific motivational considerations, we may predict that low-status group members will consider it important to emphasize their group's worth (i.e., show ingroup favoritism) in an intergroup context, while the motivation to improve their group's position may induce them to acknowledge the in-group's inferior standing (display out-group favoritism) in an intragroup context.

The central issue, then, is how to determine the circumstances under which the social context will mainly elicit a concern with the normative acceptability of group members' responses-that is, whether social context effects emerge because different contexts elicit different strategic goals. Selfcategorization theory emphasizes that, in order to understand how people's behavior is guided by their group memberships, one must know the extent to which people think of themselves in terms of that group membership. In recent research, we accordingly established that group members may respond in fundamentally different ways to identical social situations, depending on their level of in-group identification (Doosje, Ellemers and Spears 1995; Ellemers Spears and Doosje 1997; Ellemers et al. 1998; Spears, Doosje and Ellemers 1997). From these previous studies, we have accumulated converging evidence to show that those who identify strongly with the ingroup are most inclined to engage in attempts to improve their group's standing, while low identifiers are less likely to exert such effort on behalf of their group.

This distinction between low and high identifiers may help us resolve the seemingly contradictory predictions we derived above. Specifically, we would argue that high-identifying members of lower-status groups should be relatively willing to improve their group's standing. Consequently they are likely to acknowledge the in-group's inferior status among other in-group members (in an intragroup context), whereas they should insist on their group's worth in an intergroup context. By contrast, low-identifying group members may be tempted to deny their group's problems (and hence avoid taking action on behalf of the group) in an intragroup situation; for similar reasons, these group members may not be prepared to face the social costs that might be associated with defending their group's position in an inter- 
group context. Thus, in the second study, in addition to differentiating between an intragroup and an intergroup public context, we examine whether group members' responses to these two kinds of audiences differ depending on whether they are high or low identifiers.

\section{METHOD}

\section{Participants and Design}

In the second study, 184 students (76 women and 107 men; one participant did not reveal his/her gender) from various disciplines participated voluntarily. They all took part in a lottery, in which one of the participants could win a two-person skiing holiday. Eight students (six women and two men, who were distributed randomly across experimental conditions) indicated that they saw through the experimental manipulations; these were excluded from the statistical analyses. A maximum of 12 students participated in each experimental session. We used a 2 (in-group identification: high/low) by 2 (assigned status: high/low) by 3 (social context: private/ intragroup/ intergroup) between-subjects factorial design. At the end of each experimental session, all participants were fully debriefed and were asked not to discuss the experiment with fellow students.

\section{Pilot Study}

The credibility of the status manipulation was tested in a pilot study among 30 students at the University of Amsterdam, who were led to believe that students at their own university generally performed either better or worse at their practical trainee posts than those who were educated at the other Amsterdam university. With five questions they were asked to indicate the extent to which they thought the performance difference was due to internal causes (ability, effort) or external causes (difficulty, luck, validity of the investigation; $1=$ not at all; 7 $=$ very much). In general we expected that participants would make group-serving attributions if they actually believed the information they had received (see Hewstone 1990, Pettigrew 1979). Indeed we found the predicted attributional bias: Students who had received negative in-group information were more inclined to ascribe this result to differential difficulty in trainee assignments $(M=4.9)$ than were those for whom the information depicted the in-group favorably $(M=4.0, t(27)=2.14, p<.05)$. In a similar vein, the negative in-group information was attributed to differential effort $(M=4.9)$ more strongly than was positive in-group information $(M=3.6, t(27)=2.14, p<.05)$. Thus participants were more likely to "explain away" negative in-group information than positive in-group information by attributing it to external and unstable causes. In addition, many participants spontaneously commented on additional possible reasons for the alleged performance difference, attesting to the credibility of the status manipulation. From this pilot study, we thus conclude that the group status manipulation is sufficiently convincing.

\section{Procedure}

Cover story and identity measure. The experiment was presented as an investigation into the similarities and differences between students of the two Amsterdam universities, with respect to their performance during practical training outside the university. Upon arrival, participants were seated in separate cubicles. Although they were led to believe that students from both universities participated in the experiment, in fact only students from the Free University were recruited for the main study.

Participants were first asked to indicate the extent to which they identified as students of the Free University, by indicating their agreement (from 1, not at all, to 9, very much) with the four-item identity subscale developed by Luthanen and Crocker (1992); we adjusted this subscale to refer to this specific in-group. The resulting questions were "Overall, my affiliation to the Free University has very little to do with how I feel about myself" (reverse coded); "Belonging to the Free University is an important reflection of who I am"; "The Free University is unimportant to my sense of what kind of person I am" (reverse coded); and "In general belonging to the 
Free University is an important part of my self-image." We used the mean score on this measure (alpha $=.79)$ to divide participants at the median (3.25) into low $(M=2.25)$ and high $(M=4.87)$ identifiers with the in-group $(\mathrm{t}(145)=17.96, p<.0001)$.

Status manipulation. Then, participants were informed either that students at the Free University (the in-group) performed better than students at the University of Amsterdam (the out-group) at their trainee posts (high assigned status), or the reverse (low assigned status). The alleged purpose of the present experiment was to learn more about the background of these performance differences. Therefore participants were asked to work on five tasks that were said to tap qualities relevant to people's performance in practical situations, namely creativity, adaptive skills, and performance under time pressure. The actual tasks included mazes, series of figures, a brainstorming task, and a writing assignment. Neither the status manipulation nor the qualities allegedly measured with the five tasks referred to stereotypical group traits.

Social context. After completing these five tasks, participants in the private condition were told that their responses on the next two tasks would remain strictly confidential. Participants in the intragroup condition were led to believe that they would have to acknowledge and discuss their responses for the next two tasks with other in-group members, at the end of the experimental session. In the intergroup condition it was explained that each participant, at the end of the experimental session, would have to acknowledge and discuss their responses with out-group as well as other in-group participants in the same session.

Dependent measures. Participants first were asked to estimate the performance of the two groups on the five tasks that they had completed. They had to indicate the average performance of the in-group (students from the Free University) as well as the out-group (students from the University of Amsterdam) on a five-point scale ranging from 1 (very poor) to 5 (very good). Then we explained that not all participants had been working on the same set of tasks. Therefore they would be given the opportunity to rate the difficulty of different sets of tasks; we would take these ratings into account when determining the two groups relative performance. The more difficult a set of tasks was considered to be (with a minimum of 1 and a maximum of 5), the higher the number of points that could be earned with this set.

After this explanation, participants were asked to rate two sets of tasks, one that another in-group member supposedly had worked on, and one that supposedly had been completed by an out-group member. The sets that were to be judged were counterbalanced for group affiliation, and participants never were asked to rate a set they had worked on themselves.

\section{RESULTS}

\section{In-group Favoritism}

As we did in the first study, we subtracted ratings assigned to the out-group from ratings assigned to the in-group in order to examine the display of in-group favoritism with respect to performance estimates and difficulty ratings for the two groups. We subjected these two measures of in-group favoritism to a 2 (assigned status: low/high) by 2 (in-group identification: low/high) by 2 (social context: private/intragroup/intergroup) MANOVA. This analysis revealed a multivariate main effect for assigned status $(F(2,156)=8.68, p<.0001)$, and a multivariate significant three-way interaction $(F(4,312)=2.54, p<.05)$. At the univariate level, both effects were significant only for the performance estimates. That is, in the performance estimates overall, more ingroup favoritism was displayed in the high in-group status condition $(M=.23)$ than in the condition where in-group status was low $(M=-.08)$. This effect, however, is qualified by the univariate significant three-way interaction for the performance estimates $(F(2,157)=3.93, p<.05)$.

The relevant means and analysis of simple main effects (see Table 2) reveal that in the private condition, low and high identifiers show similar responses, in the sense that more in-group favoritism is displayed by those in the high assigned status condition than in the low assigned status condition (although the simple contrast is signifi- 
Table 2. Effect of Assigned Status, In-Group Identification, and Social Context on In-Group Favoritism in Performance Estimates (Experiment 2)

\begin{tabular}{|c|c|c|c|}
\hline & \multicolumn{3}{|c|}{ Social Context } \\
\hline & Private & Intragroup & Intergroup \\
\hline \multicolumn{4}{|c|}{ High In-Group Identification } \\
\hline High assigned status & $\begin{array}{l}.39^{\mathrm{a}, \mathrm{b}} \\
(.51)\end{array}$ & $\begin{array}{l}.42^{b} \\
(.52)\end{array}$ & $\begin{array}{l}.13^{\mathrm{a}, \mathrm{b}, \mathrm{c}} \\
(.50)\end{array}$ \\
\hline Low assigned status & $\begin{array}{l}.00^{\mathrm{a}, \mathrm{b}} \\
(.71)\end{array}$ & $\begin{array}{l}-.24^{\mathrm{a}} \\
(.56)\end{array}$ & $\begin{array}{l}.00^{a, b} \\
(.37)\end{array}$ \\
\hline \multicolumn{4}{|c|}{ Low In-Group Identification } \\
\hline High assigned status & $\begin{array}{l}.40^{\mathrm{b}} \\
(.51)\end{array}$ & $\begin{array}{l}-.06^{\mathrm{a}, \mathrm{c}} \\
(.73)\end{array}$ & $\begin{array}{l}.25^{b, c} \\
(.62)\end{array}$ \\
\hline Low assigned status & $\begin{array}{l}.00^{\mathrm{a}} \\
(.34)\end{array}$ & $\begin{array}{l}.00^{\mathrm{a}} \\
(.00)\end{array}$ & $\begin{array}{l}-.25^{\mathrm{a}} \\
(.45)\end{array}$ \\
\hline
\end{tabular}

a,b,c Means differ significantly from each other $(p<.05)$ if their superscripts do not share a common letter. Standard deviations are given in parentheses.

cant only for low identifiers). As predicted, however, the other two social context conditions reveal differential behavior, depending on participants' level of in-group identification. Among high identifiers, the status main effect emerges in the intragroup condition: Participants with high assigned status display more in-group favoritism than participants with low assigned status. Low identifiers do not favor their in-group, regardless of the group's relative status. The reverse pattern is found in the intergroup condition: The effect of assigned status emerges only among low identifiers, while high identifiers in both ingroup status conditions refrain from showing in-group favoritism in this condition.

The difficulty ratings resulted in a univariate significant two-way interaction only between social context and in-group identification $(F(2,157)=3.08, p<.05)$. The means pattern and the analysis of simple main effects reveal that high identifiers display significantly more in-group favoritism in their difficulty ratings in the private and intragroup conditions than in the intergroup condition (see Table 3). Low identifiers do not favor their in-group on this measure, regardless of the social context.

\section{DISCUSSION}

In this second study, the group's relative status position was assigned externally rather than being self-perceived (as in the first study). Thus the ratings given by group members in private reflect the extent to which group members internalized the group status manipulation. Some were told that their group had performed better than the other group; These participants readily incorporated this information in their private group ratings. The statement that the ingroup did worse than the other group was accepted less easily, however: Participants who had received the low group status manipulation indicated in private that they

Table 3. Effect of In-Group Identification and Social Context on In-Group Favoritism in Difficulty Ratings (Experiment 2)

\begin{tabular}{lccc}
\hline & \multicolumn{3}{c}{ Social Context } \\
\cline { 2 - 4 } In-Group Identification & Private & Intragroup & Intergroup \\
\hline High & $.14^{\mathrm{a}, \mathrm{b}}$ & $.08^{\mathrm{a}, \mathrm{b}}$ & $-.06^{\mathrm{c}}$ \\
& $(.25)$ & $(.29)$ & $(.30)$ \\
Low & $.05^{\mathrm{a}, \mathrm{b}, \mathrm{c}}$ & $-.03^{\mathrm{a}, \mathrm{b}, \mathrm{c}}$ & $.05^{\mathrm{b}}$ \\
& $(.19)$ & $(.26)$ & $(.26)$ \\
\hline
\end{tabular}

a,b,c Means differ significantly from each other $(p<.05)$ if their superscripts do not share a common letter. Standard deviations are given in parentheses. 
considered their group as worthy as the other group. Thus, even though these group members did not indicate that they considered their group superior to the other group, we would argue that their refusal to acknowledge unfavorable information about the in-group in their private judgments should be considered a form of in-group favoritism.

The main goal of the second study was to investigate how these private judgments would be adapted in different social contexts; we argued that this outcome would be influenced both by the nature of the audience and by the extent to which people identify with the group. In accordance with our hypothesis that high- and low-identifying group members are likely to be concerned with different goals, we found that public displays of in-group favoritism are determined interactively by the level of in-group identification and by the public context in which the groups are rated. Low identifiers seem mainly to adapt their public behavior to what the audience in question is likely to appreciate, while they refrain from responding in a way that might be sanctioned by others (also see Reicher and Levine 1993, 1994). Towards other in-group members (in an intragroup context) they indicate that the ingroup is as worthy as the other group, but they do not seem to be prepared to defend this view in front of an out-group audience (in an intergroup context).

Although high identifiers also show different responses depending on the public context, they admit to the in-group's problematic current standing only in an intragroup context. This may seem counterintuitive at first sight; as we argued in the introduction, however, such common acknowledgment that the status quo has unfavorable implications for the in-group might constitute a first step towards collective action aimed at improving the group's standing. In fact, converging empirical evidence suggests that those who identify strongly with their group are more prepared than low identifiers to stay together and exert such effort on the group's behalf when the group finds itself in an unfavorable situation (see Barreto and Ellemers forthcoming, Ellemers, Spears and Doosje 1997;
Ouwerkerk, Ellemers and De Gilder, 1999). At the same time, in an intergroup context -that is, when out-group members are also involved-high identifiers do not admit to the in-group's inferiority. Hence they also seem prepared to incur the social costs that might be associated with standing up for their group in public.

We obtain a similar pattern of results for the difficulty ratings. Those who identify strongly with their group think privately that their group may have been disadvantaged; they seem also to use this position for themselves in an intragroup context to explain the unfavorable current outcome of the intergroup comparison. Nevertheless, just as they will not acknowledge in front of the other group that their group seems to be doing worse, they accordingly do not claim that this difference is due to unjust treatment in an intergroup context. In sum, the results of this second study support our argument that a public context can affect people's intergroup judgments in different ways, depending on the nature of the implied audience implied as well as the level of in-group identification.

Although the results on the two measures of in-group favoritism are generally consistent with our predictions, at the same time they show two slightly different patterns; only the performance estimates reflect the status manipulation. This can be explained when we consider that the performance estimates essentially refer to the outcome of the current intergroup comparison. Therefore, on this measure, group members can hardly avoid taking into account the status differences of the groups involved. By contrast, the difficulty ratings depend less directly on current performance differences; this may help us understand why they are governed primarily by levels of in-group identification and social contextual aspects, rather than by relative group status.

\section{GENERAL CONCLUSIONS}

The results of these two studies complement each other in showing that the presence of an audience can constrain the ways in which group members express their identity needs. We demonstrated that the extent 
to which people display in-group favoritism in their group ratings is determined not only by their group's status position, but also by the social context in which they give these ratings and by the importance of this particular group for their identity.

In previous investigations in which lower-status group members failed to display in-group favoritism (for overviews see Hinkle and Brown 1990; Mullen et al. 1992) one could not rule out the possibility that this occurred because the group members themselves doubted the value of their group. Indeed, such an explanation would be consistent with Tafjel and Turner's (1979) suggestion that members of lower-status groups may come to internalize their inferior social standing, and hence refrain from attempts to establish a better position for the in-group. In the present investigation we aimed to address this issue more directly; we included private as well as public group ratings in order to distinguish between internally held convictions and public expressions of the ingroup's worth. Our findings enable us to conclude that lower-status group members respond strategically to the social situation in which they find themselves, while privately believing that their group is just as good as the other group (Study 2) or even better (Study 1).

Public responses in the first study revealed that people are likely to refrain from behavior that would seem unacceptable to the out-group, in keeping with previous empirical evidence on the expression of normative in-group attitudes (Reicher and Levine 1994).

In the second study we examined these strategic responses in closer detail by comparing what people communicate about their group to different audiences. As we argued on the basis of Tajfel and Turner's assumption that in striving for positive group distinctiveness, people must identify with the group in question, we found that whether or not people emphasize the worth of a lower-status in-group depends on their level of in-group identification. The responses given by low-identifying group members are least likely to meet with resistance from the audience in question: In an intragroup context, these individuals maintain the in- group's value; in an intergroup context, they acknowledge their group's inferior standing to an audience that also contains out-group members.

By contrast, those who identify more strongly with their group seem more prepared to incur (social) costs that may be associated with defending the in-group's worth. Among themselves (in an intragroup context) they acknowledge that the ingroup's current standing is unfavorable; this situation as they indicate, might be due to unjust treatment, and may prepare the ingroup for taking social action. To the outside world, however (in an intergroup context) they maintain that their group is as valuable as the other group (also see Ellemers, Barreto, and Spears 1999).

The goal of the present study was to examine whether the relation between group status and the occurrence of in-group favoritism might be inconsistent because the motivation to achieve positive in-group distinctiveness in itself is not sufficient to elicit public claims of in-group superiority. Instead we argued that, given the same motivation to view the in-group in a positive light (which indeed emerged consistently in private ratings of the groups), people's expressive behavior in public situations also depends on other factors. The results of these two studies emphasize that the strategies which group members are likely to use in order to meet their identity needs depend on the audience constraints posed by the social situation in which they find themselves and on their level of in-group identification.

\section{REFERENCES}

Barreto, Manuela and Naomi Ellemers. Forthcoming. "You Can't Always Do What You Want: Psychological and Contextual Determinants of the Choice to Work on Behalf of a Low-Status Group." Personality and Social Psychology Bulletin.

Brewer, Marilynn B. 1979. "In-group Bias in the Minimal Intergroup Situation: A CognitiveMotivational Analysis." Psychological Bulletin 86:307-24.

Crocker, Jennifer and Riia Luhtanen 1990. "Collective Self-Esteem and Ingroup Bias." Journal of Personality and Social Psychology 58:60-67. 
Doosje, Bertjan, Naomi Ellemers and Russell Spears 1995. "Perceived Intragroup Variability as a Function of Group Status and Identification." Journal of Experimental Social Psychology 31:410-36.

Ellemers, Naomi. 1993. "The Influence of SocioStructural Variables on Identity Enhancement Strategies." European Review of Social Psychology 4:27-57.

Ellemers, Naomi, Manuela Barreto and Russell Spears 1999. "Commitment and Strategic Responses to Social Context." Pp. 127-46. In: Social Identity: Context, Commitment, Content, edited by Naomi Ellemers, Russell Spears and Bertjan Doosje. Oxford: Blackwell.

Ellemers, Naomi, Russell Spears and Bertjan Doosje 1997. "Sticking Together or Falling Apart: Group Identification as a Psychological Determinant of Group Commitment versus Individual Mobility." Journal of Personality and Social Psychology 72:123-40.

Ellemers, Naomi, Wendy van Rijswijk, Jan Bruins and Dick de Gilder 1998. "Group Commitment as a Moderator of Attributional and Behavioural Responses to Power Use." European Journal of Social Psychology 28:555-73.

Ellemers, Naomi and Wendy van Rijswijk 1997. "Identity Needs versus Social Opportunities: The Use of Group-Level and Individual-Level Identity Management Strategies." Social Psychology Quarterly 60:52-65.

Ellemers, Naomi, Wendy van Rijswijk, Marlene Roefs and Catrien Simons 1997. "Bias in Intergroup Perception: Balancing Group Identity with Social Reality." Personality and Social Psychology Bulletin 23:186-98.

Goffman, Ervin. 1959. The Presentation of Self in Everyday Life. Garden City, N.Y.: Doubleday.

Haslam, S. Alexander and John C. Turner. 1992. "Context-dependent Variation in Social Stereotyping 2: The Relationship Between Frame of Reference, Self-categorization and Accentuation." European Journal of Social Psychology 22:3-20.

. 1995. "Context-dependent Variation in Social Stereotyping 3: Extremism as a Selfcategorical Basis for Polarized Judgment." European Journal of Social Psychology 25:341-371.

Hewstone, Miles. 1990. "The Ultimate attribution error? A Review of the Literature on Intergroup Causal Attribution." European Journal of Social Psychology 20:311-35.

Hinkle, Steve and Rupert J. Brown. 1990. "Intergroup Comparisons and Social
Identity: Some Links and Lacunae." Pp. 48-70 in Social Identity Theory: Constructive and Critical Advances, edited by D. Abrams and M.A. Hogg. New York: Harvester.

Lemaine, Gerard. 1974. "Social Differentiation and Social Originality." European Journal of Social Psychology 4:17-52.

Long, Karin and Russell Spears. 1997. "The SelfEsteem Hypothesis Revisited: Differentiation and the Disaffected." In The Social Psychology of Stereotyping and Group Life, edited by Russel Spears, P.J. Oakes, Naomi Ellemers and S.A. Haslam. Oxford: Blackwell.

Luthanen, Riia and Jenifer Crocker. 1992. "A Collective Self-esteem Scale: Self-evaluation of one's Social Identity." Personality and Social Psychology Bulletin 18:302-18.

Messick, David M. and Diane M. Mackie. 1989. "Intergroup Relations." Annual Review of Psychology 40:45-81.

Mullen, Brian, Rupert Brown and Colleen Smith. 1992. "In-group Bias as a Function of Salience, Relevance, and Status: An Integration." European Journal of Social Psychology 22:103-122.

Mummendey, Amelie and Hans-Joachim Schreiber. 1983. "Better or Different? Positive Social Identity by Discrimination Against or Differentiation from Outgroups." European Journal of Social Psychology 13:389-97.

. 1984. “'Different' just means 'Better': Some Obvious and Some Hidden Pathways to In-group Favoritism." British Journal of Social Psychology 23:363-68.

Mummendey, Amelie and Simon, Bernd. 1989. "Better or Different? III: The Impact of Importance of Comparison Dimension and Relative In-group Size Upon Intergroup Discrimination." British Journal of Social Psychology 28:1-16.

$\mathrm{Ng}$, Sik Hung. 1986. "Equity, Intergroup Bias, and Interpersonal Bias in Reward Allocation." European Journal of Social Psychology 16:239-55.

Oakes, Penny. 1987. "The Salience of Social Categories." Pp. 117-41. In Rediscovering the Social Group: A self-Categorization Theory, edited by J.C. Turner, M.A. Hogg, P.J. Oakes, S.D. Reicher, and M.S. Wetherell. Oxford: Basil Blackwell.

Oakes, Penny J., S. Alexander Haslam and John C. Turner. 1994. Stereotyping and Social Reality. Oxford: Blackwell.

Ouwerkerk, Jaap, Naomi Ellemers and Dick de Gilder. 1999. "Group Commitment and Individual Effort in Experimental and Organizational Contexts." Pp. 184-204 in Social Identity: Context, Commitment, Content, edited by Naomi Ellemers, Russell 
Spears and Bertjan Doosje. Oxford: Blackwell.

Pettigrew, Thomas F. 1979. "The Ultimate Attribution Error: Extending Allport's Cognitive Analysis of Prejudice." Personality and Social Psychology Bulletin 5:461-76.

Plant, E. Ashby and Praticia G. Devine. 1998. "Internal and External Motivation to Respond Without Prejudice." Journal of Personality and Social Psychology 75:811-32.

Reicher, Steven D. and Mark Levine. 1993. "On the Consequences of Deindividuation Manipulations for the Strategic Communication of Self: Identifiability and the Presentation of Social Identity." European Journal of Social Psychology 24:511-24.

. 1994. "De-individuation, Power Relations Between Groups and the Expression of Social Identity: The Effects of Visibility to the Out-group." British Journal of Social Psychology 33, 145-64.

Reicher, Steven D., Russell Spears and Tom Postmes. 1995. "A Social Identity Model of Deindividuation Phenomena." European Review of Social Psychology 6:161-98.

Spears, Russell, Bertjan Doosje and Naomi Ellemers. 1997. "Self-Stereotyping in the Face of Threats to Group Status and Distinctiveness: The Role of Group Identification." Personality and Social Psychology Bulletin 23:538-53.

Spears, Russell, Martin Lea and S. Lee. 1990. "Deindividuation and Group Polarization in Computer-Mediated Communication." British Journal of Social Psychology 29:121-34.

Spears, Russell and Anthony S.R. Manstead. 1989. "The Social Context of Stereotyping and Differentiation." European Journal of Social Psychology 19:101-21.

Tajfel, Henri. 1974. "Social Identity and Intergroup Behavior." Social Science Information 13:65-93.
1975. "The Exit of Social Mobility and the Voice of Social Change." Social Science Information 14:101-18.

. 1978. "Social Categorization, Social Identity and Social Comparison." Pp. 61-76 in Differentiation Between Social Groups: Studies in the Social Psychology of Intergroup Relations, edited by Henri Tajfel. London: Academic Press.

Tajfel, Henri, and John C. Turner. 1979. "An Integrative Theory of Social Conflict." Pp. 33-47 in The social psychology of intergroup relations, eidted by W. Austin and S. Worchel. Monterey, CA: Brooks/Cole.

Turner, John C. 1987. "The Analysis of Social Influence." Pp. 68-88 in Rediscovering the social group: A self-categorization theory, edited by John C. Turner, M.A. Hogg, P.J. Oakes, S.D. Reicher and M.S. Wetherell. Oxford: Blackwell.

Van Knippenberg, Ad and Huub van Oers, Huub. 1984. "Social Identity and Equity Concerns in Intergroup Perceptions." British Journal of Social Psychology 23:351-61.

Van Knippenberg, Ad, and Henk Wilke. 1979. "Perceptions of Collégiens and Apprentis Re-analyzed." European Journal of Social Psychology 9:427-34.

Van Knippenberg, Ad. 1989. "Strategied of Identity Management." In Ethnic Minorities: Social Psychological Perspectives, edited by J.P. van Oudenhoven and Tineke M. Willemsen. Amsterdam: Zwets and Zeitlinger.

Van Knippenberg, Ad and Naomi Ellemers. 1990. "Social Identity and Intergropu Differentiation Processes." European Review of Social Psychology 1:137-69.

Young, Heather, Ad van Knippenberg, Naomi Ellemers and Nanne de Vries. 1997. "The Effects of Group Membership and Social Context on Information Organization." European Journal of Social Psychology 27:523-37.

Naomi Ellemers is a Professor of Social and Organizational Psychology at Leiden University, in Leiden, the Netherlands. Her research intersts are in the area of intergroup relations and social identity processes.

Cathy van Dyck is an affiliate at the Free University of Amsterdam, the Netherlands. She graduated in 1995 at the Free University (Vrije Universiteit) Amsterdam, the Netherlands, where she has done research on Social Identity Theory. Since then, and during her PhD at the University of Amsterdam, her area of research has been organizational culture aspects of error handling, error management, the learning organization and attribution of failure. 
Steve Hinkle is a Professor of Psychology at Miami University in Oxford, Ohio, USA. His research interests have emphasized intergroup processes, particularly the relationship between identification with a group and prejudice.

Annelieke Jacobs was a student at The Free University, Amsterdam, when working on this research. 